\title{
Clinical Manifestations and Outcomes of Patients with Mycosis Fungoides in Mansoura, Egypt
}

\author{
Shereen Ezzalregal Alashry, MD1 . Engy Mossad Aboelnaga, MD². Wafaa Elbeshbeshi, MD2 ${ }^{*}$
}

\author{
${ }^{1}$ Department of Dermatology, Andrology \\ and Sexually transmitted diseases, Facul- \\ ty of Medicine, Mansoura University. \\ ${ }^{2}$ Department of Clinical Oncology and $\mathrm{Nu}$ - \\ clear Medicine, Faculty of Medicine, Man- \\ soura University.
}

\begin{abstract}
Background: Mycosis fungoides(MF) is considered as the most prevalent form of cutaneous T-cell lymphoma. It is well known that diagnosis of MF is difficult due to its extremely diverse manifestations and non-specific histopathological findings. Besides, MF has a chronic relapsing course, and afflicted patients are often receiving multiple as well as consecutive drug regimens.

Objective: To assess the demographic profiles, skin-directed therapies, systemic therapies, and the response to therapy in patients with MF.

Methods: This retrospective study was performed on cases with pathological confirmation of MF. Patients' data were collected from Clinical Oncology and Dermatology departments, Mansoura University Hospital from January 2006 to December 2013.

Results: A total of 55 cases(30 males and 25 females) with mean age of 45.07 years at time of diagnosis were reviewed. The majority $(89 \%)$ of patients had an early-stage (I and II) MF. Forty-four (80\%) patients had classic MF; 7 (12.7\%) hypo-pigmented MF; and 4 (7.3\%) other variants. Initial diagnosis of other skin diseases was $41.8 \%$. Phototherapy was the commonest line of therapy used for those patients. At the final assessment, 7 (12.7\%) patients had complete response; whereas 48 (87.3\%) had partial response. Conclusion: MF might clinically and histopathologically simulates benign skin diseases mainly in early stages. Precise clinico-pathological correlation is necessary to support the diagnosis. Treatment of MF is principally determined by the disease extension and its effect on quality of life, as well as patient's age and other comorbid conditions. Skin-directed therapies applied in early-stage MF can give prolonged remissions, although disease cure is unclear.

Key words: Mycosis fungoides; Cutaneous; T-cell lymphoma; Phototherapy; Systemic therapies; Prognosis.
\end{abstract}

\section{Introduction}

It is worth mentioning that primary cutaneous lymphomas (PCL)are scarce types of non-Hodgkin lymphomas( $2 \%)$ and account for $18 \%$ of extranodal non-Hodgkin lymphomas, which found in the patient's skin at time of diagnosis, without extracutaneous affection. These lymphomas include both primary cutaneous T-cell lymphoma $(80 \%)$ and B-cell lymphoma (20\%) [1]. Mycosis fungoides(MF) was first described by Alibert about 200 years ago[2], and it is the most frequent type of cutaneous T-cell lymphoma (CTCL), represent- ing approximately $50-60 \%$ of $\mathrm{PCL}[3]$.

MF presents as solitary, focal, or multifocal patches, plaques, nodules, or tumors on any cutaneous site. Lesions of MF usually present by a variety of colors, most commonly as a shade of red, but also as hyper-pigmented, hypo-pigmented, or yellow patches. Ulceration is uncommon in patches or plaques of MF, but frequent in the tumor stage disease [4].

The disease typically affects middle-aged adults, but may present at any age with male predominance. Moreover, the incidence of MF varies eth- 
nically and regionally with higher rates among blacks[5]. Diagnosis of MF is established by skin biopsy, followed by staging workup, which may include radiologic imaging studies and assessment of blood, lymph nodes, bone marrow, and internal organs for any systemic involvement as indicated by initial patient presentation [3].

The most important prognostic factors that impact survival include: patient's age at time of presentation, area and type of skin affection, overall stage (TNM-staging classification), presence of any extra-cutaneous or peripheral blood affection [6,7]. MF is generally characterized by an inactive prolonged course for years, with no standardized therapy providing a consistent survival advantage exists. Therefore, the primary consideration for the treatment of MF is to prevent disease progression to more advanced stages and to preserve the quality of patient's life as long as possible [4, 8]. Therapy must be tailored to each patient with carefully weighing the risk-benefit ratio. Therapies offering fewer known adverse effects with greater potential benefits should be attempted first, while aggressive multi-agents chemotherapy contributing to immunosuppression should be reserved for end-stage palliation [8].

Generally, treatment of MF is classified into both skin directed and systemic therapies. Skin directed therapy (SDT) is the main regimen applied for treatment of the early disease stage, however systemic therapy is used in the advanced stages [8]. Systemic therapy is subdivided according to the mechanism of action into: biological modifiers as rexinoid, retinoids, and interferons; histone deacetylase inhibitors; and traditional chemotherapeutic agents as gemcitabine and doxorubicin).SDTs such as: corticosteroids, topical retinoids, carmustine, nitrogen mustard, and rexinoid(bexarotene) are commonly used, also body irradiation and ultraviolet light therapy[8-10]. MF is extremely radiosensitive and radiotherapy is the most effective single agent for treatment of early disease stage. It is well known that total skin electron beam therapy (TSEBT) is efficient especially in cases with thick generalized plaque (T2) or tumorous disease (T3) [11].

Median survival in patients with stage IA disease is more than 12 years and no decrease in survival when compared to a matched control population. It is now appreciated that for patients with stage $\mathrm{IB}$, the existence of plaques (T2b) is correlated with bad prognosis and increased risk of disease progression in comparison to cases with patches only (T2a) ${ }^{[12]}$. In contrast, patients with more advanced stage of MF (stages IIB, III, and IVA) usually have a median survival time of 5 years, and stage IVB patients have a median survival of 2.5 years. More specifically, cases with positive nodes (N1) also have bad survival in comparison to those with no palpable nodes (N0) [12-14].

This study was designated to retrospectively assess the demographic profiles, skin-directed therapies, systemic therapies, the response to therapy and course of the disease of patients with MF in our institution presenting to a tertiary referral unit, Mansoura University hospital in Egypt.

\section{Patient and Methods:}

This retrospective study involved patients with pathological confirmation of MF between January 2006 and December 2013. Patients' data were collected from Clinical Oncology and Dermatology departments, Mansoura University hospital. Clinical data included: age, sex, duration of symptoms, presence of itching, positive lymph nodes or organomegally, sign of disease and percent of affected body surface area (BSA) were obtained.

We also retrieved details of investigation either: laboratory tests (complete blood count, liver and kidney function, LDH and ESR, percent of eosinophilic cells), radiological studies (including chest $\mathrm{X}$-ray or $\mathrm{CT}$, when indicated, abdominal ultrasound or $\mathrm{CT}$, if needed), pathology details (the number of biopsies required for establishing the diagnosis and immunohistochemistry detection of positive CD 4 or 8 at initial diagnoses were also documented) and bone marrow biopsy. Types of 
treatment given and response of treatment were recorded. Different lines were administrated either SDTs (as topical treatment, PUVA, radiotherapy or local chemotherapy) or systemic-chemotherapy after failure of local therapy.

The staging of CTCLs was decided depending on the type and extent of skin affection.TNM classification primarily published in 1979 and modified later in 2007 by the International Society for Cutaneous Lymphomas(ISCL) and the European Organization of Research and Treatment of Cancer (EORTC) by adding variable degrees of blood affection(TNMB) [3], was used in the study.

\section{Lines of treatment:}

- Topical treatment: in the form of corticosteroids, tazarotene gel, bexarotene gel and local application of vepsid ampules.

- Phototherapy: either narrow band ultraviolet $B$ (NB-UVB) or psoralen ultraviolet A (PUVA).

Both database records and patients' medical charts were revised to get information concerning skin phototype, narrow-band UVB treatment regimen (cumulative UVB dose, treatment duration as well as number of treatments),PUVA treatment regimen(psoralen dose, cumulative UVA dose, treatment duration as well as number of treatments), as well as response to treatment.Cases with considerable co-morbidities or any contraindication to psoralen administration as: children, pregnant females, and hepatic patients were treated with narrow-band UVB. Typically, when the lesion had cleared, treatment regimen was paused till clinical relapse was noticeable.

- Combined therapy: systemic retinoids or interferons in addition to phototherapy.

- Localized radiotherapy:30Gy/3 weeks/15 treatments(6-10 MeV)

- Total skin electron beam radiotherapy.

- Chemotherapy: either mono-chemotherapy e.g. methotrexate $50 \mathrm{mg} /$ week, gemcitabine
$1000 \mathrm{mg} / \mathrm{m}^{2} \mathrm{~d} 1,8,15$ or multi-agent chemotherapy e.g. CVP (cyclophosphamide750 mg/m² i.v d1, vincristine $1.4 \mathrm{mg} / \mathrm{m}^{2}$ i.v. $\mathrm{d} 1$ and prednisone $40 \mathrm{mg} / \mathrm{m}^{2}$ p.o d1-5)or CHOP(cyclophosphamide $750 \mathrm{mg} / \mathrm{m}^{2}$ i.v. d1, doxorubicin $50 \mathrm{mg} /$ $\mathrm{m}^{2}$ i.v. $\mathrm{d} 1$, vincristine $1.4 \mathrm{mg} / \mathrm{m}^{2} \mathrm{i} . \mathrm{v}$ d1 \& prednisone $100 \mathrm{mg} / \mathrm{m}^{2}$ p.o. d1-5)

\section{Evaluation of response}

Response was assessed based on the clinical criteria. Complete response (CR) was described as disappearance of more than $95 \%$ of skin lesions; partial response (PR) was defined if more than $50 \%$ of skin lesions were cleared even with continuation of treatment; no response was considered if less than $50 \%$ of skin lesions were cleared, with persistent skin affection inspite of continuing treatment. While relapsed disease was determined as clinically important disease necessitating subsequent therapy

\section{Statistical analysis:}

Data analysis was performed using SPSS (statistical program for social science version 16). Quantitative variables were presented as means \pm standard deviation (SD) or medians, while qualitative variables were described as number and percentage. Chi-Square test was used to compare between groups. All $p$ values were considered significant when less than 0.05 .

\section{Results}

A total of fifty-five cases with clinical and pathological confirmation of MF were reviewed. Table 1 shows the demographic profile and clinical features of all cases. Thirty (54.5\%) patients were males and $25(45.5 \%)$ were females. The mean age of cases at time of diagnosis was $45.07 \pm 17.25$ years. The median disease duration from appearance of the first symptoms and signs was 4 years (mean: $4.09 \pm 3.5$ years). Besides, no patient had history of HIV or other forms of immunosuppression; however four (7.3\%) patients 
were HCV positive.No family history of lymphoma or skin cancer in any of the study patients was reported. The lesions in 28 (50.9\%) patients were itchy. Forty-four (80\%) patients presented with classic MF (patches, plaques and/or tumors). The mean BSA affected by MF was $43.29 \% \pm$ $27 \%$ (range: $6 \%-90 \%$ ). The majority of patients $(89 \%)$ had stage I\&II at time of diagnosis, with 2 (3.6\%) patients had stage IIla and $4(7.3 \%)$ patients had stage IIlb. In $23(41.8 \%)$ patients, an initial diagnosis of eczema, atopic dermatitis, psoriasis, parapsoriasis, pigmented purpura and pityriasis lichenoided were reported. As regard hypo-pigmented MF, vitiligo, pityriasis alba and leprosy were diagnosed initially. In fact more than one biopsy was required to establish the diagnosis in $33(60 \%)$ patients. The mean duration of follow up was $30.56 \pm 19.62$ months (range: 6-90 months). At the final assessment; complete response was reported in $7(12.7 \%)$ patients, partial response in $48(87.3 \%)$ patients (alive with disease), and none showed progressive disease.

Table 2 summarizes the different treatment modalities used in our patients. PUVA was the commonest line of therapy. It was used in $30(54.5 \%)$ patients followed by topical treatment in 26
(47.3\%) patients. Chemotherapy was administered in $15(27.3 \%)$ patients. Combined therapy, narrow-band UVB, localized radiotherapy, and total body radiation were applied in 12 (21.8\%), 11 (20\%), 8 (14.5\%), and $6(10.9 \%)$ patients respectively. Interestingly, many patients had received more than one treatment regimen at different intervals of their disease.

Comparison between male and female patients showed insignificant difference as regard duration of the disease, affected body surface area and stage distribution. There was significant difference in age of the patients between male and female as depicted in Table 3.

Table 4 shows the differences between classic MF and hypo-pigmented MF. There was significant difference in the age of the patients and types of MF. No statistical difference was observed in the mean duration of the disease and affected BSA. The correlation between staging of MF and presence of itching versus eosinophilia and high LDH is demonstrated in Table 5. There were significant correlations between staging of MF with eosinophilia and high LDH. On the other hand, there was insignificant correlation between presence of itching and high LDH or eosinophilia. 
Table 1: Clinical characteristics of patients with MF

\begin{tabular}{|c|c|}
\hline Clinical characteristics & No (\%) \\
\hline $\begin{array}{l}\text { Age at diagnosis (years): } \\
\text { Mean } \\
\text { Range }\end{array}$ & $\begin{array}{l}45.07 \pm 17.25 \\
8-65\end{array}$ \\
\hline $\begin{array}{l}\text { Sex: } \\
\text { Male } \\
\text { Female }\end{array}$ & $\begin{array}{l}30(54.5 \%) \\
25(45.5 \%)\end{array}$ \\
\hline $\begin{array}{l}\text { Disease duration (years): } \\
\text { Mean } \\
\text { Range }\end{array}$ & $\begin{array}{l}4.09 \pm 3.5 \\
1-10\end{array}$ \\
\hline $\begin{array}{l}\text { Types of MF: } \\
\text { Classic } \\
\text { Hypopigmented } \\
\text { Others } \\
\end{array}$ & $\begin{array}{ll}44 & (80 \%) \\
7 & (12.7 \%) \\
4 & (7.3 \%)\end{array}$ \\
\hline $\begin{array}{l}\text { Number of biopsies: } \\
1 \\
2 \\
3\end{array}$ & $\begin{array}{l}22(40 \%) \\
27(49.1 \%) \\
6 \quad(10.9 \%)\end{array}$ \\
\hline $\begin{array}{l}\text { Initial diagnosis of MF } \\
\text { Initial diagnosis of other diseases }\end{array}$ & $\begin{array}{l}32(58.2 \%) \\
23(41.8 \%)\end{array}$ \\
\hline $\begin{array}{l}\text { Staging: } \\
\text { Ia } \\
\text { Ib } \\
\text { IIa } \\
\text { IIb } \\
\text { IIIa } \\
\text { IIIb }\end{array}$ & $\begin{array}{ll}7 & (12.7 \%) \\
16 & (29.1 \%) \\
18 & (32.7 \%) \\
8 & (14.5 \%) \\
2 & (3.6 \%) \\
4 & (7.3 \%)\end{array}$ \\
\hline Eosinophilia & $20(36.4 \%)$ \\
\hline High LDH & $19(34.5 \%)$ \\
\hline $\begin{array}{l}\text { Body surface area }(\%) \text { : } \\
\text { Mean } \\
\text { Range }\end{array}$ & $\begin{array}{l}43.29 \pm 27 \\
6-90\end{array}$ \\
\hline $\begin{array}{l}\text { Duration of follow up(months): } \\
\text { Mean } \\
\text { Range }\end{array}$ & $\begin{array}{l}30.56 \pm 19.62 \\
6-90\end{array}$ \\
\hline $\begin{array}{l}\text { Response to treatment: } \\
\text { Complete response } \\
\text { Partial response }\end{array}$ & $\begin{array}{l}7(12.7 \%) \\
48(87.3 \%)\end{array}$ \\
\hline
\end{tabular}


Table 2: Treatment modalities used for MF

\begin{tabular}{|l|cl|}
\hline Treatment modality & N & \% \\
\hline Topical treatment & 26 & 47.3 \\
Narrow-band UVB(NB-UVB) & 11 & 20 \\
Psoralen plus UVA(PUVA) & 30 & 54.5 \\
Combined therapy* & 12 & 21.8 \\
Localized radiotherapy & 8 & 14.5 \\
Total body radiation & 6 & 10.9 \\
Chemotherapy & 15 & 27.3 \\
& & \\
\hline
\end{tabular}

${ }^{*}$ Combined therapy means PUVA plus interferons or retinoids

Table 3: Comparison between male and female patients

\begin{tabular}{|c|c|c|c|}
\hline $\begin{array}{l}\text { Clinical } \\
\text { characteristics }\end{array}$ & $\begin{array}{l}\text { Male } \\
(\mathrm{n}=30)\end{array}$ & $\begin{array}{l}\text { Female } \\
(\mathrm{n}=25)\end{array}$ & $P$ \\
\hline $\begin{array}{l}\text { Duration of disease } \\
\text { (mean in years) }\end{array}$ & $4.3 \pm 4.04$ & $3.84 \pm 2.82$ & 0.634 \\
\hline $\begin{array}{l}\text { BSA } \\
\text { (mean in percent) }\end{array}$ & $45.63 \pm 27.22$ & $40.48 \pm 27.1$ & 0.487 \\
\hline Age (mean in years) & $50.23 \pm 14.35$ & $38.88 \pm 18.64$ & $0.014^{*}$ \\
\hline $\begin{array}{l}\text { Stage: No (\%) } \\
\text { Ia } \\
\text { Ib } \\
\text { IIa } \\
\text { IIb } \\
\text { IIIa } \\
\text { IIIb }\end{array}$ & $\begin{array}{l}2(6.7) \\
9(30) \\
8(26.7) \\
7(23.3) \\
1(3.3) \\
3(10)\end{array}$ & $\begin{array}{l}5(20) \\
7(28) \\
10(40) \\
1(4) \\
1(4) \\
1(4)\end{array}$ & 0.23 \\
\hline
\end{tabular}

* Significant $\mathrm{P}<0.05$ 
Table 4: Comparison between both classic and hypo-pigmented MF patients

\begin{tabular}{|l|l|l|l|}
\hline Clinical characteristics & $\begin{array}{l}\text { Classic MF } \\
\mathrm{n}=44)\end{array}$ & $\begin{array}{l}\text { Hypo-pigmented } \\
\text { MF (n=7) }\end{array}$ & $\boldsymbol{P}$ \\
\hline $\begin{array}{l}\text { Duration of disease ( } \\
\text { mean in years) }\end{array}$ & $4.09 \pm 3.64$ & $4.42 \pm 2.93$ & 0.817 \\
\hline $\begin{array}{l}\text { BSA } \\
\text { mean in percent) }\end{array}$ & $45.29 \pm 26.65$ & $13.85 \pm 25.34$ & 0.219 \\
\hline Age (mean in years) & $48.81 \pm 16.06$ & $22.85 \pm 11.18$ & $0.000^{*}$ \\
\hline
\end{tabular}

* Significant $P<0.05$.

Table 5: Staging of disease and presence of itching in correlation to high LDH and presence of itching

\begin{tabular}{|lr|l|l|}
\hline $\begin{array}{l}\text { Clinical } \\
\text { characteristics }\end{array}$ & LDH & Eosinophilia \\
\hline Staging & $\mathrm{r}$ & 0.479 & 0.475 \\
\cline { 3 - 4 } & $p$ & $0.000^{*}$ & $0.000^{*}$ \\
\hline Itching & $\mathrm{r}$ & 0.102 & 0.014 \\
\cline { 3 - 4 } & $p$ & 0.461 & 0.921 \\
\hline
\end{tabular}

* Significant $P<0.05$. 


\section{Discussion}

CTCLs are a diverse group of non-Hodgkin lymphomas originated from skin-homing $\mathrm{T}$ lymphocytes. The most common types of CTCL are MF and Sezary Syndrome (SS). Till now, precise diagnosis of CTCL is problematic because of the different clinical presentations of the disease as well as the deficiency of specific genetic and immunephenotypic markers [13]. This study summarized the epidemiology, natural history, as well as clinical criteria and staging of MF, besides reviewing different lines of treatment in a tertiary referral center. It hoped to set up a data base which would serve as a tool to assess clinical outcomes and improve the health care quality delivered to patients with MF.

In the present study, we have demonstrated that MF occurred mostly in adults with male predominance and the mean age of patients was 45.07 \pm 17.25 years. Forty-four (80\%), 7 (12.7\%) and 4 $(7.3 \%)$ patients presented with classic, hypopigmented MF, and other presentations, respectively. Bradford et al. reported that MF usually afflicts old males(median age: 55-60 years at time of diagnosis), with a male: female ratio of $\sim 2: 1$ [14]. Interestingly, the mean age of hypopigmented MF cases recorded in our study was $22.85 \pm 11.18$ years at time of diagnosis. We agreed with the previous studies reported the unusual high frequency of hypo-pigmented MF in children, especially among dark-skinned[15,16], which was responsible for the decrease in the mean age in comparison with others [14].

Hypo-pigmented MF may be erroneous with different benign diseases as vitiligo, or pityriasis alba. Vitiligo is frequently confused with hypopigmented MF in patients with dark complexion. El-Darouti et al. described several features to distinguish both. Vitiligo manifests as depigmented macules due to the absence of melanocytes and melanin pigment. However, hypo-pigmented MF presents as hypo-pigmented macules, which are due to partial loss of melanocytes and melanin. Moreover, epidermotropism, hydropic degeneration of basal layer, maintenance of considerable melanocytes, dermal fibrosis and existence of lymphocytes in the papillary dermis are seen more in hypo-pigmented MF in comparison with vitiligo. The loss of pigmentation in hypopigmented MF is probably because of the cytotoxic activity of CD8+T-cells to melanocytes [17].

In our study, the frequency of multiple biopsies was $60 \%$ either two or three to establish the diagnosis of MF. Initial diagnosis of other diseases was $(41.8 \%)$. This is in agreement with Nashan et al. who reported that diagnosis of MF depends on linking clinical manifestations, histopathological examination and gene rearrangement results together [18]. Histopathologically, MF is distinguished by the existence of large abnormal lymphocytes, lymphocytic infiltrates in the papillary dermis and thick collagen fibers. Although, in early stage of MF it is infrequently to find all these pathological changes and differentiation from an inflammatory condition is usually hard [19]. It is worth mentioning that the detection of a monoclonal T-cell infiltrate is not specific for diagnosis of lymphomas. Moreover, positive polymerase chain reaction (PCR)findings have been reported in several diseases including pityriasis lichenoides et varioliformis acuta (PLEVA),psoriasis, and lichen ruber[20]. Kotz et al. stated that lymphoma should be considered in each chronic disease resistant to treatment [21]. Zackheim and McCalmont named MF as 'the great imitator' [22].

Concerning the staging of the disease, we found that the majority of patients $(89 \%)$ had stage I, II at time of diagnosis. These data agree with the findings of others studies, which reported that the high proportion of patients referred with earlystage disease [23, 24, and 25]. In our study, there was significant difference in age of patients between males and females. This is in agreement with previous studies, which suggested that wom- 
en are more commonly to manifest at earlier age than men [26], also black women are the distinctly possible to reveal early onset disease[27].

Agar et al. found that females have good prognostic factors concerning the disease-specific survival, the overall survival rate, as well as the risk of disease progression, however; this result was independently significant for survival on multivariate statistical analysis [24]. Improved overall survival rate has been also reported in females in a population-based study of 1,479 cases with MF [28] , and in those with nodal lymphomas and other malignancies. This has been referred to the estrogen effects on the immune system as well as the pharmacodynamics of chemotherapy [29].

We have demonstrated significant correlations between staging of MF with eosinophilia and high LDH level. Tancrede-Bohin et al. revealed that presence of blood eosinophilia in patients with MF held a risk ratio of 7.33 and 10.57 for both disease specific-progression and-death, respectively [30]. Zampella and Hinds also reported that eosinophilia is a prognostic marker for more advanced disease forms in cases with MF, increased number of therapies, and lower response to treatment regimens [27]. Consistent with previous data concerning cutaneous and systemic lymphomas [31, 32], higher level of serum LDH was recorded to be an independent prognostic marker for survival and progression risks.

Cases with MF frequently experience extreme symptoms linked to their disease (e.g.pruritus, pain, fatigue, and sleep disturbance), the social stigmata of having prominent hideous skin lesions, and the psychological as well as the emotional problems of living with a chronic and potentially fatal disease [3]. Pruritus in our study was detected in $28(50.9 \%)$ of patients and there was insignificant correlation between presence of itching and high LDH level or eosinophilia. These data agree with the findings of Al Ghamdi et al., which revealed that pruritus was absent in $50 \%$ of cases with MF.Thus, a non-pruritic nature of MF can help differentiating between MF and eczema, a condition that is commonly mistaken with early MF [33].

Management of MF and SS is extremely difficult and there is no simple algorithm or current cure. Therapeutic strategies for both early and late stage MF as well as SS and choosing specific agents were developed by cooperating networks and certain organizations in the United States as the National Comprehensive Cancer Network (NCCN) and the United States Cutaneous Lymphoma Consortium (USCLC) [34]. Treatment of MF and SS depends mainly on the disease extent and its effect on quality of life, prognostic factors (e.g.large cell transformation or folliculotropic $M F)$, and patient's age as well as comorbidities. Early stage MF (stages IA-IIA)has good prognosis with using SDTs as first-line treatment regimen where prolonged complete remissions have been reported, yet disease cure is uncertain [35].

In our study, we have estimated the frequency of treatment modalities used for MF. PUVA was the commonest line of therapy. It was used in 30 $(54.5 \%)$ patients followed by topical treatment in $26(47.3 \%)$ patients. Chemotherapy was administered to $15(27.3 \%)$ patients. Combined therapy (PUVA plus interferons or retinoids), narrow-band UVB, localized radiotherapy, and total body radiation were applied in 12 (21.8\%), 11 (20\%), 8 $(14.5 \%)$, and $6(10.9 \%)$ patients, respectively. Many patients have received more than one treatment regimen at different times of the disease course.

Wong et al.reported that immunity has an important role in disease progression, and chemotherapeutic agents that keep or boost the immune response as interferons and retinoids, are more preferable than those causing immune depression as the cytotoxic agents [13]. Advanced stages of MF and SS (stages IIB-IVB)are frequently resistant to treatment with bad prognosis. Current approaches compromise immunobiologic treatment and gene-targeted therapies, however the dura- 
tion of clinical response is usually short. Accordingly, multi-agent chemotherapy should be kept for cases refractory to treatment, as treatment aims at lowering the tumor burden, postponing disease progression, as well as maintaining quality of life [37].

\section{Conclusions}

MF may clinically and histopathologically simulates different benign skin diseases, hence continuing to challenge the dermatologist. Clinicopathological correlation is highly indicated to assist in diagnosis, mainly in early stages of the disease. Treatment of MF is mainly determined by stage of the disease, the impact on quality of life, and patient's age/co-morbidities. The current treatment of MF is quite diverse. SDTs in early-stage MF can give prolonged remissions with favorable prognosis, although disease cure is unclear.

\section{Ethical standards}

Formal consent is not required for this type of study.

\section{Disclosure}

The authors have no conflicts of interest to be declared.

\section{References}

1-Willemze R, Hodak E, Zinzani PL, Specht L, Ladetto M (2013). ESMO Guidelines Working Group Primary cutaneous lymphoma: ESMO clinical recommendations for diagnosis, treatment and follow-up. Ann Oncol.; 24: vi149-vi154.

2- Lessin SR. Alibert lymphoma: Renaming mycosis fungoides (2009). Arch Dermatol; 145: 209-210.

3-Olsen E, Vonderheid E, Pimpinelli $\mathrm{N}$ et al (2007). Revisions to the staging and classification of mycosis fungoides and Sezary syndrome: a proposal of the International Society for Cutaneous Lymphomas (ISCL) and the cutaneous lymphoma task force of the European Organization of Research and Treatment of
Cancer (EORTC). Blood; 110(6):1713-22.

4-Franck N, Carlotti A, Gorin I et al (2005). Mycosis Fungoides-type cutaneous T-cell lymphoma and Neutrophilic Dermatosis. Arch Dermatol; 141:353-356.

5- Imam MH, Shenoy PJ, Flowers CR, Phillips A, Lechowicz MJ (2013). Incidence and survival patterns of cutaneous T-cell lymphomas in the United States. Leuk Lymphoma; 54(4):752759.

6-de Coninck EC, Kim YH, Varghese A, Hoppe RT (2001). Clinical characteristics and outcome of patients with extracutaneous mycosis fungoides. J ClinOncol; 19(3):779-784.

7- Kim YH, Liu HL, Mraz-Gernhard S, Varghese A, Hoppe RT(2003). Long term outcome of 525 patients with mycosis fungoides and Sezary syndrome: clinical prognostic factors and risk for disease progression. Arch Dermatol; 139(7):857-866.

8-Trautinger F, Eder J, Assaf C et al (2017). European Organisation for Research and Treatment of Cancer consensus recommendations for the treatment of mycosis fungoides/Sézary syndrome - Update. European J Cancer; 77:57-74.

9- Keehn CA, Belongie IP, Shistik G, Fenske NA, Glass LF (2007). The diagnosis, staging, and treatment options for mycosis fungoides. Cancer Control; 14(2):102-111.

10- Rosen ST, Querfeld C(2006). Primary Cutaneous T-Cell Lymphomas. Hematology; 1:323330.

11- Mazzeo E, Rubino L, Buglione M et al (2014). The current management of mycosis fungoides and Sézary syndrome and the role of radiotherapy: Principles and indications. Rep Pract Oncol Radiother; 19(2): 77-91.

12- Arulogun SO, Prince HM, Ng J et al (2008). Long-term outcomes of patients with advanced-stage cutaneous T-cell lymphoma and large cell transformation. Blood; 112 (8) : 3082-7.

13- Pulitzer M (2017). Cutaneous T-cell Lympho- 
ma. Clin Lab Med; 37(3): 527-546.

14-Bradford PT, Devesa SS, Anderson WF, Toro JR (2009). Cutaneous lymphoma incidence patterns in the United States: a populationbased study of 3884 cases. Blood; 113: 506473.

15-Ardig M, Borroni G, Muscardin LM, Kerl H, Cerroni $L(2003)$. Hypopigmented mycosis fungoides in Caucasian patients. A clinicopathologic study of 7 cases. J Am Acad Dermatol; 49:264-270.

16.Fink-Puches R, Chott A, Ardig M, Simonitsch I, Ferrara G, Kerl H et al(2004). The spectrum of cutaneous lymphomas in patients less than 20 years of age. PediatrDermatol; 21:525-533.

17-El-Darouti MA, Marzouk SA, Azzam O, Fawzi MM et al(2006). Vitiligo vs. hypopigmented mycosis fungoides (histopathological and immunohistochemical study, univariate analysis). Eur J dermatol; 16:17-22.

18-Nashan, DS, Stander S, Luger TA and Stadler $R$ (2007). Mycosis fungoides: a dermatological masquerader. B Journal of Dermatol; 156: $1-10$.

19-Naraghi ZS, Seirafi H, Vakikhani $M$ et al (2003). Assessment of histologic criteria in the diagnosis of mycosis fungoides. Int $\mathrm{J}$ Dermatol; 42:45-52.

20- Dereure O, Levi E, Kadin ME (2000). T-cell clonality in pityriasis lichenoides et varioliformis acuta: a heteroduplex analysis of 20 cases. Arch Dermatol; 136:1483-6.

21-Kotz EA, Anderson D, Thierst BH (2003). Cutaneous T-cell lymphoma. J Eur Acad Dermatol Venereol; 17:131-7.

22-Zackheim HS, McCalmont TH (2002). Mycosis fungoides: the great imitator. Am Acad Dermatol 2002; 47:914-18.

23-Alsaleh QA, Nanda A, Al-Ajmi H, Al-Sabah H (2010). MF: Clinicoepidemiological features of mycosis fungoides in Kuwait, 1991-2006. Int J Dermatol; 49: 1393-8.

24-Agar NS, Wedgeworth E, Crichton S, Mitchell TJ et al (2010). Survival Outcomes and Prog- nostic Factors in Mycosis Fungoides/Sezary Syndrome: Validation of the Revised International Society for Cutaneous Lymphomas/ European Organisation for Research and Treatment of Cancer Staging Proposal J Clin Oncol; 28:4730-9.

25-Quaglino P, Pimpinelli N, Berti E, CalzavaraPinton $P$, et al(2012).Time Course, Clinical Pathways, and Long-Term Hazards Risk Trends of Disease Progression in Patients With Classic Mycosis Fungoides. Cancer; 118 (23):5830-9.

26-Sun G, Berthelot C, Li Y, Glass DA II, et al (2009).Poor prognosis in non Caucasian patients with early-onset Mycosis fungoides. J Am AcadDermatol; 60:231-5.

27-Zampella JG, Hinds GA (2013). Racial differences in mycosis fungoides: A retrospective study with a focus on eosinophilia. J Am AcadDermatol; 68:967-71.

28-Weinstock MA, Reynes JF (1999). The changing survival of patients with mycosis fungoides: A population based assessment of trends in the United States. Cancer; 85:208-12.

29-Khamly K, Thursfield V, Fay M et al (2009). Gender specific activity of chemotherapy correlates with outcomes in chemosensitive cancers of young adulthood. Int $\mathrm{J}$ Cancer; 125:426-431.

30-Tancrede-Bohin E, Ionescu MA, de La Salmoniere $\mathrm{P}$, Dupuy $\mathrm{A}$, et al(2004). Prognostic value of blood eosinophilia in primary cutaneous T-cell lymphomas. Arch Dermatol; 140:105761.

31-Shipp MA, Harrington DP, Anderson JR et al (1993). A predictive model for aggressive nonHodgkin's lymphoma: The International NonHodgkin's Lymphoma Prognostic Factors Project. N Engl J Med 329:987-994.

32-Vidulich KA, Talpur R, Bassett RL et al (2009). Overall survival in erythrodermic cutaneous $\mathrm{T}$ cell lymphoma: An analysis of prognostic factors in a cohort of patients with erythrodermic cutaneous T-cell lymphoma. Int J Dermatol; 
48:243-252.

33- AlGhamdi KM, Arafah MM, Al-Mubarak LA, Khachemoune A et al(2012). Profile of mycosis fungoides in 43 Saudi patients. Ann Saudi Med; 32(3): 283-287.

34-Olsen EA, Rook AH, Zic J, Kim Y et al (2011). Sezary syndrome: immunopathogenesis, literature review of therapeutic options, and recommendations for therapy by the United
States Cutaneous Lymphoma Consortium (USCLC). J Am Acad of; 64, 352-404.

35- Jawed SI, Myskowski PL, Horwitz $S$ et al (2014). Primary cutaneous T-cell lymphoma (mycosis fungoides and Sezary syndrome) Part II. Prognosis, management, and future directions. J Am AcadDermatol; $70: 223$. e1-17. 